\title{
A Turn in Teaching and Learning : The Transnational Classroom in an International Setting
}

\section{Korsberg, Hanna}

Palgrave Macmillan

2017-11-22

Korsberg , H \& Lahtinen , O 2017 , A Turn in Teaching and Learning : The Transnational Classroom in an International Setting . in S Bala , M Gluhovic , H Korsberg \& K Röttger (eds) , International Performance Research Pedagogies: An Unconditional Discipline? . Palgrave Macmillan, pp. 189-202.

http://hdl.handle.net/10138/311621

unspecified

acceptedVersion

Downloaded from Helda, University of Helsinki institutional repository.

This is an electronic reprint of the original article.

This reprint may differ from the original in pagination and typographic detail.

Please cite the original version. 


\section{A Turn in Teaching and Learning: Transnational Classroom in an International Setting}

Hanna Korsberg \& Outi Lahtinen, University of Helsinki

When the theatre research disciplines in Finland (Theatre Research at the University of

Helsinki and Theatre and Drama Research at the University of Tampere) entered Erasmus Mundus programme MA in International Performance Research (hereafter MAIPR) we faced a need to both redefine the study object of the discipline and to become more conscious about the pedagogy we used to teach it. Even though the disciplines at the Finnish universities had included also studying other than drama performances, drama theatre was nevertheless in the core of the disciplines, whereas the other performances were in the margins. MAIPR reversed this setting placing drama theatre as one among many kind of performances and took us also to look and discuss performances of everyday life. In terms of the pedagogy a new approach was needed because of the variety of backgrounds and interests that the students brought with them in the classroom; instead of a group of students who came from a coherent educational, cultural and societal background limited by the small shared language like Finnish, the students now came from all over the world with varying cultural, societal and academic or practice oriented BA backgrounds. We also found that the disciplinary redefinition and the shift in the pedagogy were in many ways intertwined.

In this article we discuss the challenges of pedagogy in internationalization in higher education, especially regarding the performance research. We consider the practical pedagogical choices we identify in the curriculum and our teaching methods of MAIPR 2008-13. Considering the increase in international higher education, there is still at the moment very little discussion on the pedagogy of it. Not surprisingly, the discussion has 
emerged in the fields of geography as well as language and culture. After discussing the transnational pedagogy and the internationalizing the higher education in general we describe our pedagogical choices in the MAIPR: establishing blended learning design and appropriating the idea of flipped classroom. To conclude, we describe how the joined learning process established by the pedagogy contributes to the progress and quality of the internationalization of theatre and performance studies.

Transnational pedagogy as a concept is a debated one. It has several meanings, some of them even conflicting in the context of higher education. In this article, the concept is used to discuss cross-cultural teaching. (Dashwood et al, 2008, p. 99) In this understanding formulated by Ann Dashwood, Jill Lawrence, Alice Brown and Lorelle Burton from the University of Southern Queensland, Australia, the ideas of transnational and pedagogy are seen as intertwined and equated with good inclusive pedagogical practices, as opposed to a more traditional viewpoint where 'transnational' refers only to the offshore location of teaching but does not interfere with the conception or practices of the pedagogy. (Dashwood et al, 2008, p. 102, 103.)

In this article the concepts of international and transnational and their complementarity are of essence. As Janelle Reinelt pointed out in her MAIPR key lecture, the origin of the term 'international' is in jurisprudence. Reinelt interprets it as follows:

It signifies more than one nation, and implies cooperation or at the least negotiation between and among multiple entities called nations. It avoids working within the global/local binary rejecting its two-term polarity and hierarchical struggle in favour of a multiplicity of gradations. (Reinelt 2008, p. 4.)

We use the international to describe the structure established by the institutional agents of the MAIPR. The transnational, again, refers to the movement across the national borders, especially by the people and their knowledge and ideas. At the time of her lecture, Reinelt 
paid attention to the fairly recent increase of the use of the term and emphasized how it charts "the flow of movement itself", simultaneously rendering the borders less important. (Reinelt 2008 , p. 5.) Hence, in our understanding the international institutional platform of MAIPR was created in order to serve the transnational interaction of individuals.

The internationalization of the higher education has been criticized of being a thoroughly Western pursuit. In the context of discussing the higher education of geography, it has been said to originate from the needs of the Western society in the age of globalization, and to be the response of the Western educational system to these needs without questioning if the globalization and its consequences is equally beneficial worldwide. Also, it has been claimed that the ultimate goal of globalization is to promote the Western worldview and lifestyle as such, and above all, its commercial aspect, hence, to produce a world full of Western-kind of consumers. (Jackson, 2003, p. 326; Haigh, 2003, p. 332.) However, Martin Haigh makes a difference between two dimensions of internationalization. On one hand, there is the commodification of higher education that makes it a valuable product in the international export-import market. On the other hand, there is the individual teachers' viewpoint where internationalization process provides students with benefits of multicultural understanding and international contacts. (Haigh, 2003, p. 331.) Also M. G. Jackson sees the possibility to question and create alternative meanings to supersede the commercial ones to be located in the classroom and to emerge from the joint learning processes between the teachers and the students (Jackson, 2003, p. 329). This latter kind of process we can identify our own experience as teachers in the MAIPR programme. We also suggest, that with chosen pedagogical structures and practices the internationalization does not produce a new form of colonization but works on reshaping the constitution of the discipline. 
Our programme resisted the reduction to an exported academic commodity by the constitution of its classroom both in the concrete as well as metaphoric sense. First of all, the inscribed objective of MAIPR was to internationalize the conception of theatre and performance studies as an academic field however remaining sensitized to the complexities, limitations and compromises as well as to the possibilities of the task. The resistance to commodification was made structural and took place in respect of the teachers as well as the students. With no doubt, institutionally MAIPR was a Western pursuit, or more precisely a European pursuit, in terms of the collaborating European universities and EU funding institutions. However, regarding the teachers and students it was not limited to the economic and political union nor to the European continent.

Also, the concept of Western MAIPR associates with differs from "the Western" discussed by Jackson, Haigh, Dashwood, Lawrence, Brown and Burton who all come from the anglophonic discourse. MAIPR suggests that neither "the western" is a uniform and unanimous monolith but a get-together of several traditions that had to face and negotiate their differences in the course of the programme. There were four different home universities, all located in different parts of Europe, adhering to different, sometimes competing academic heritages and with research focus on different performance and theatre traditions. The fragmentation of the concept of Western was proliferated by the academic nomadism of many of the core teachers who had studied in one or more academic cultures and worked still in another. It is also worth reminding that the Erasmus Mundus -programs are, by definition, mobility programs between Europe and Third Countries. Thus, the visiting scholars had to be based outside of the European Union, so coming from outside of Europe they expanded the worldview of the program. All together the teachers came from five different continents. Due to this, it is impossible to consider MAIPR as a western home university going offshore 
teaching. If anything, it was a combination of several academic and cultural homes and nomadism that created a platform for conceptual and practical work on diverse manifestations of performance.

In addition to the international staff of the programme the students contributed in the diversifying of the academic and performance cultures of the classroom. First of all, they came from a variety of cultures and academic backgrounds, and second, they all brought with them their own cultural perspective and expertise to the discipline, the international performance research. The performance concepts and practices that were introduced to the classroom discussion by the students coming from all over the world were an elementary part in the formation of objects of interest that were explored. Thus, the basis for the transnational pedagogy was created already by the structure of the programme. It shaped the understanding of classroom as well. The classroom varied from a physical classroom of sometimes less than ten students to a virtual classroom including 30 participants in three different locations. Therefore, the "transnational" of the programme is not a place somewhere away from home, but really an encounter of several nationalities, ethnicities and cultural backgrounds.

Consequently, the transnational classroom of the programme is to be understood as a space of interaction and communication between the participants.

The concept of pedagogy matters here as well. If teaching and learning are understood as a process of knowledge transfer from those who know (the teachers) to those who do not yet know (the students), the institutional structure dominates and might build a case of off-shore teaching referred to by Dashwood et al. However, when the concept and practices of pedagogy are understood as a joined learning process between the students and the teachers, international program like MAIPR can be seen as a platform provided by the organizing 
institutions but used for the transnational interaction of all the participants in terms of shared knowledge production.

\section{With blended learning design to a growing competence of individual students}

In the classroom constellation described above, the focus of the pedagogy is transferred from the teaching of contents to the growth and development of the individual students and their competence. Karen Risager writes about parallel development in the language and culture pedagogy where "such concepts as intercultural competence and the intercultural speaker: a person who is able to mediate between various languages and various cultural contexts" have become the objective of the discipline. (Risager, 2007, p. 10) She outlines the current language and culture pedagogy to be interested not only in language and culture, but also in society and the individual subject:

It is thus also interested in national and ethnic issues, not only in the sense of national and ethnic communities, identities and discourses but also the societal and political structures that form frameworks and conditions for identity constructions. It places the national and the ethnic in a larger global perspective, and deals with the multilingual and multicultural subject as a world citizen. (Risager, 2007, p. 3)

This broad scope equals the interests of international performance research. The performances with which the discipline concerns itself, take place in various national and ethnic communities, they are parts of different historically shaped societal and political structures that frame their production, and they reflect, represent and participate in the construction of different kinds of identities. These contexts not only define the outer circumstances for the creation of the performances but also provide both clues and limits to their interpretation as discursive "cultural resource bataillons" (Lehtonen, 2000, p. 111, 114115). The students as well as the teachers bring to the curriculum their respective knowledge 
about the performance practices and the functions the performances may have in the contexts with which they are familiar.

This knowledge about various local and communal performance conceptions and practices is then brought together with the conceptual, analytical and critical discussion of the discipline and explored in relation to the transnational cultural flows. Transnational cultural flow is a concept coined by Ulf Hannerz, and according to Risager it is "an attempt to make visible cultural practices and processes that cut across national structures". (Risager, 2007, p. 17) Its purpose is to illuminate

how various cultural flows are spread via social networks of varying extents - from personal interaction at the micro-level to communication processes, mobility and the transportation of commodities at higher levels: national, transnational, transcontinental and global. (Risager, 2007, pp. 16-17)

The performance activity in its various forms participates in these flows in the transnational communities and/or on the global market in several ways, both in terms of structures and individual interaction. The interculturally competent performance scholars and practitioners aspired by MAIPR are trained to recognize the levels of these flows and to operate in and with them.

The pedagogy to carry out this curriculum we found successful can be described as blended learning design. It combined traditional teacher led lectures, students' own case study projects in groups and individually, and flipped classroom, which we found useful particularly in modules that were designed to create continuity to the curriculum from the students' viewpoint. The flipped classroom, also sometimes called inverted classroom, shifts the emphasis to the preparation. This is not new as such: teachers have required students to read materials before coming to classes even before the pedagogy was specifically named. 
However, defining certain practices as a specific pedagogy is in connection with determinately shifting the focus from teacher-held lectures to discussions where students participate actively. As one of the foremost spokesmen of the flipped classroom, physicist Eric Mazur has captured then "the class time can be devoted to discussions, peer interactions, and time to assimilate and think.”(Mazur, 2009, p. 51). In our teaching, as in the performance studies in general, for instance, seeing performances together and conceptualizing and contextualizing them was an essential way for the discipline to implement the flipped classroom pedagogy in practice.

On the level of the Finnish MAIPR syllabus, the flipped classroom featured especially in the courses that were designed to launch or close a module. There the teachers prepared first and foremost the course structure, including assignments and learning objectives, and also brought some of the conceptual and case study material for the class, but the students were required to prepare as well, not only by reading what the authors convey in their texts, but also by preparing their own examples to bring into the discussions. This rearranges the energy, initiative and hierarchies in the classroom. The teachers remain in charge of the intellectual quality of the classroom, but at the same time they are exposed to a situation and discussion of which they are not the initiators, but to which they react. This way the teachers become learners as well, and the classroom becomes a joined learning process.

The suitability of the inverted classroom for an introductory course has been questioned (Strayer 2012, p. 191). We partly share this viewpoint. In our experience, the flipped classroom, particularly in the case of the common to all induction week, tended to stress the students both due to the workload and in terms of learning tasks that did not take shape clearly from the students' viewpoint. However, when the staff learned to facilitate the 
students' working process providing more meta-level instructions and encouraging the students to accept their confusion and frustration as a productive phase of learning, the pedagogy proved its advantages. Especially, in terms of our discipline, the international performance research, the flipped classroom pedagogy set the scene of performance immediately as heterogeneous and diverse. It created a playing field where the performance concepts and concrete performance examples introduced by the participants, both students and teachers, encountered. Making sense of this multitude was much more challenging than advancing little by little, nevertheless, it was much more productive in terms of conceiving the field of study as essentially broad and multifaceted, not as (primary) cores and (secondary) margins.

In Helsinki autumn 2012, we taught together two courses, Key Theories in International Performance Research and Performance, Festival, Curation, Text. These courses were designed first, to launch the modules they were a part of, and second, to sum up and reflect the whole contents of the module, the latter concerns especially the assignments to complete these courses. In the first course, the students presented their performance analysis cases in written form and they were given individual feedback after which they completed the final version. In the second course the assignment was to create a portfolio: the students prepared case studies which were oriented according to their own cultural and academic interests and included also their reflection on their learning process in the module. These portfolios were presented to the group and discussed in association to the theoretical literature that concerned different key concepts of the module. Thus, the students were supposed to prepare and present material for the discussions; it was their task to choose the examples. At the classroom the teachers mainly taught by asking questions rather than by providing answers. The new knowledge and understanding was produced by the use of peer teaching and 
learning. As teachers we experienced that one of our main tasks was, first, to create an atmosphere where the students felt themselves trustful enough to make their best effort for the assignments and consider them important, second, to respond with questions and comments so that they felt themselves seriously and properly heard and received, and third, to assist in and confirm that they recognized and acknowledged their own learning processes. Thus the flipped classroom served especially as a space of summing up and reflecting on the contents of the larger unit, the module. As for us as the teachers, this reflection produced immediate feedback regarding the success of the pedagogy.

In terms of the curriculum of the whole programme, the Induction week and the summer school employed flipped classroom kind of pedagogical idea. The aim was to activate the students and to get them to know each other not only as smaller groups but also as a whole cohort. Especially the Summer School extended the scale of the students' individual responsibility and consequently continued the gradual growth of their agency.

Since the aim of the programme includes both academic as well as more practice oriented training, the learning environment was meant to develop diverse skills to communicate. This served the overall goal which was to educate transculturally competent agents who can contribute to the various fields of international performance production and research. Students also tested the learning outcomes outside the academic classrooms and universities during their internships which provided a future learning environment. During the internships they socialized into the different professions of the discipline. As the internship was scheduled in the middle of the second term the students could reflect their experiences with each other and the teachers and so connect this knowledge as an organic part of their learning processes in the programme. 
The influence of varying national, ethnic and other kind of communities keeps on having relevance in the international and transnational framework of the discipline. Karen Risager reminds that apart from EU and UN, the "national political structures constitute the only frameworks for representative democracy", and while democracy, according to Risager, is itself at risk from behalf of the neo-liberal globalism, it is worth to concern oneself with it. (Risager, 2007, p. 190-191.) So, the bearings of the national culture may be seen in the sense of community and solidarity beyond societal and ethnic boundaries (Risager, 2007, p. 190191), but also, as must be remembered, in some cases as oppressive and restrictive power. We can only agree with Risager, who, in spite of her interest in the paradigmatic change from national to transnational, suggests maintaining the national as "an important focal point", nevertheless, "accompanied by an awareness of" its contingent nature. (Risager, 2007, p. 195.) This contingency became also manifested in the individual works of the MAIPR students at the same time when the students deepen their ability in participating in the knowledge production of the discipline.

The shift of the focus of the discipline from theatre to performance is often constructed in binaries, where theatre is destined to represent the old, disciplinary, Western and conservative, whereas performance stands for new, interdisciplinary, non-Western and progressive (Jackson 2004, p. 24). Shannon Jackson wants to challenge this division as obfuscating: "It threatens, for instance, to ignore the scholarly and institutional efforts of those whose work addresses issues of gender, race, sex, class, and globalization from within the theatre context." (Jackson 2004, p. 25) She provides a row of examples to illustrate the possible bypasses:

An expansion of the genre of drama to the realm of performance may permit the recognition of non-Western cultures. However, if Western/non-Western too easily maps to 
drama/performance, then the work of, say, an African playwright is relegated to a conceptual blindspot. For some institutions, the adoption of a performance studies perspective went hand in hand with a feminist curricular revision. However, those masculinist origin stories [--] suggest that it is just as possible to align performance studies with macho, homophobic quest to dissociate from the feminized realm of theatre. Indeed, the gendered, racial, and sexual relations between theatre and performance studies are intensely varied, contextual, and complicated. (Jackson 2004, p. 25)

These threads concern Finnish theatre studies as well, especially in terms of class and gender. The specifics of the Finnish field of performing arts in general is that it is dominated by theatre which is not an artform of limited elites or only a phenomena of the capital area but has been considered to concern the whole population of the nation. Theatre has participated in the negotiations of the identity of the nation and its citizenship since the idea of an independent Finland was raised in the 19th century. Beside the Finnish National Theatre there was a vivid tradition of workers' theatre movement which formed one root for a tight network of municipal theatres around the country. In addition to that, the field of performing arts has diversified by the emergence of smaller theatre groups. The economical and political support from the state and municipalities can be considered as a token of the significance of the art form. This has also provided circumstances for theatre repertories to focus not primarily on light entertainment but also to give their audiences food for thought. Based on the amount of sold tickets, this is also what the audiences seem to expect from the theatres. In a country with approximately 5.45 million inhabitants there are roughly 3.6 million tickets to theatre, dance, circus and opera productions sold annually. ${ }^{1}$ Also, female playwrights have an internationally exceptionally strong position in the Finnish drama canon since its beginning. Thus, in comparison to the better known and bigger European theatre cultures, like German, British and French, the Finnish theatre culture has its unique features and ignoring them would be a loss. Therefore, introducing these features to the students of international

\footnotetext{
${ }^{1}$ The Theatre Info Finland, TINFO, publishes yearly Finnish theatre statistics including the amount of sold tickets. www.tinfo.fi/en/Theatre Statistics. 13.11.2015.
} 
performance research and going together to see the performances deconstructs the often homogenous understanding of what is meant with the "European theatre".

\section{Conclusions: A joint learning process to the participation in the transnational cultural} flows

The flipped classroom as an element to create continuity of the blended learning design proved to be a successful pedagogical decision in teaching instead of or beside the traditional information-transfer model of education. It was an essential support for the curriculum of the programme both in terms of the transnational pedagogy and in the constitution of the discipline. A productive way to demonstrate the questions of national and transnational was to look at them in the context of performance cultures and traditions that the participants of the classroom, both students and teachers, were able to introduce to the others. This resulted to a joint learning process where everybody participated in the learning community. We can confirm Jeremy F. Strayer's insight, that inverted /flipped classroom encourages cooperation in both preferred learning environment and in classroom experience. Also, we agree with his observation that it improves the students' recognition of the value of learning together with others for example in innovation and persuades them to be more open to different learning activities in the future. (Strayer, 2012, p. 190) According to Strayer, compared to students in traditional classrooms the students in inverted/flipped classroom become more aware of their own learning processes. (Strayer 2012, pp. 191-192) We hope that learning more about their learning and studying skills not only assisted the MAIPR graduates to recognize and adapt the different academic cultures but also will benefit them in the future life, in and outside the academic world. 
The joint learning process operated not only within one cohort of students and the teachers, but continues beyond the cohorts both among the teachers and, as far as we know, among the students. Carrying out the program as an international collaboration increased the transnational interaction between the academics of the field. Based on the feedback from the students and the annual evaluations, the Joint Academic Board and the collegial community of teachers discussed the teaching of the discipline and the curriculum of the programme, thus the accumulating reserve of the documented study experiences of the students participated in developing the programme further. As for the students, they have created a virtual space for the alumni of the MAIPR where the discussion continues among the different cohorts of the programme. Hence, MAIPR has become not only an environment where to learn about performances as part of the transnational cultural flows, but it has itself also become a social network to which the students and teachers alike engage as intercultural agents on the individual level thus actively participating in the creation and direction of those flows.

Bibliography:

Dashwood, Ann, Lawrence, Jill, Brown, Alice, Burton, Lorelle (2008) Transnational Pedagogy from Policy to Practice: Beginnings of the Journey. International Journal of Pedagogies and Learning, 4(3) July 2008, pp. 97-110.

Haigh, Martin (2003) Internationalising the University Curriculum: response to M. G. Jackson. Journal of Geography in Higher Education, vol 27. No 3, November 2003, pp. 331340.

Jackson, M. G. (2003) Internationalising the University Curriculum. Journal of Geography in Higher Education, vol 27. No 3, November 2003, pp. 325-330.

Jackson, Shannon (2004) Professing Performance. Theatre in the Academy from Philology to Performativity. Cambridge: Cambridge University Press.

Lehtonen, Mikko (2000) Cultural Analysis of Texts. London: Sage Publications Ltd. Mazur, Eric (2009) Farewell, lecture? Science 2009, 323:50-51.

Reinelt, Janelle (2008) First Keyword Lecture. A MAIPR faculty lecture 2008. A Manuscript. Risager, Karen (2007) Language and culture pedagogy: from a national to a transnational paradigm. Clevedon: Multilingual Matters, cop.

Strayer, Jeremy F. (2012) How learning in an inverted classroom influences cooperation, innovation and task orientation. Learning Environments Research 2012; 15:171-193. 
